\title{
Development of Teaching Materials for Need-Oriented Training to Improve the Learning Pedagogic Competence
}

\author{
Joko Sutarto \\ \{jokotarto@mail.unnes.ac.id\} \\ Department of Non-formal Education Universitas Negeri Semarang \\ Gedung A Kampus Sekaran, Gunungpati Semarang 50229, Indonesia
}

\begin{abstract}
Training materials oriented to the needs of participants are the main prerequisites for the successful implementation of training. The research objectives were: (a) to identify training teaching materials needed by the tutelary community in improving pedagogical competence, and (b) test the effectiveness of training teaching materials to improve the tutelage pedagogical competencies. The source of research data is 16 tutors. Data collection is done through interviews, documentation, and tests. The research procedure follows the flow of literature studies, serve the field, and preparation of training teaching materials, and test the effectiveness of teaching materials. The research findings show: (a) the training material needs most felt by the tutors towards mastery of pedagogic competencies are in the learning competency sub-competence especially in analyzing students' initial abilities, and (b) training teaching materials, in terms of the response of trainees responsive (84\%); and seen from the comparison of the pre-test and post-test scores showed a score of 0.4789 in the high category; thus it can be stated that training instructional materials were developed effectively to improve the learning skills of the tutor's pedagogics.
\end{abstract}

Keywords: training teaching materials, effectiveness, pedagogic competence.

\section{Introduction}

The success of organizing and managing non-formal education units is a reflection of the ongoing implementation of sustainable performance guidance. Such guidance is a necessity in improving quality in the global era which is characterized by increasingly fierce competition in all aspects of life. It is realized that the success of learning services is inseparable from fostering the quality of learning performance of the tutors. The good performance of tutors will be able to develop the potential of students as optimally as possible. The success of nonformal education units in providing a large contribution to improving the knowledge, attitudes, and skills of students.

Empirical facts show that the training of tutor learning that has been conducted so far has not been marked yet there is no specific training tool for teaching materials that accommodates the characteristics and needs of trainees [1]. Such conditions indicate the existence of training objectives held with preparation equipment, especially teaching materials. Theoretically and empirically the training teaching materials used affect training or special actions on academic achievement and practical skills [2]. It was stated that the academic achievements of the trainees were strongly influenced by the psychological 
atmosphere or work climate which was supported by the training materials that matched the expected needs of the trainees [3]. The scope of the problem in this study is related to the design and needs of training teaching materials which are expected to improve the pedagogical competence of the learning community.

The objectives of this study were: (a) to identify the training needs needed by the tutelary community in improving pedagogical competence, and (c) test the effectiveness of teaching materials in improving the tutelage pedagogical competencies. $\mathrm{n}$ general, training is part of education that describes a learning process to improve a person in completing work. Training is a process that creates conditions and stimuli to generate responses to other people, develop knowledge and skills and attitudes, create behavioural changes, and achieve specific goals. The definition above provides an understanding that the main idea in training is the existence of a process that is used to meet needs or goals.

Training is an intentional, purposeful and controlled effort so that other people learn, and relatively permanent behavioural changes occur as a result of experience [4]. Efforts to make other people learn can be done by someone who can design, develop, utilize, manage, and assess the learning process. It was emphasized that if the training participants felt that there was a match between the characteristics and needs of the training material, they could be expected to achieve satisfactory achievements. Management empowerment and human resources through appropriate training can improve organizational performance, low organizational performance caused by poor quality planning and a less supportive organizational climate [5].

Need identification is a process and procedure that is prepared to prioritize needs and decision making about programs and allocation of resources needed for continuity of training programs. Identification is an integral part of the organizing process and planning will subsequently be made as a reference in the preparation of training programs. The activity of conducting training teaching materials is a collaborative activity between learning resources, while the learning program becomes its product. By considering the importance of training teaching materials for the smooth running of activities and objectives, it is necessary to be optimal in current learning needs and important environmental potential and sharpness of analysis. In designing learning for adults who have low learning motivation, ask for three lessons, namely proposing a problem-centred, learning projective, and accessing selfactualization [6].

Effective training teaching materials will have an impact on the sustainability of the conducive learning process, and ultimately have a further impact on mastering the competencies of trainees. This is consistent with research findings that show that teaching materials are designed effectively can help participants connect what they already know to what they expect in learning, and to build new knowledge from analysis and synthesis in the learning process [7][8]. The contribution of mastery or competence in educational practices in the form of responsibility and accountability by utilizing technology will support professional services [9].

Training not only increases knowledge and skills but also develops talent, training correlates with improving the competency of trainees [10]. Competence is a description of the qualitative nature of a person's behaviour. do something, which results from the learning process. During the learning process, the stimulus will join the contents of the memory and cause changes in the capacity to do something. Pedagogic competence in this study is defined as knowledge, skills, and basic values that are reflected in the habit of thinking and acting. In detail, each sub-competency is described as an important indicator of pedagogical competence 
as follows: (a) understanding students in-depth, (b) designing learning, (c) implementing learning.

\section{Method}

This research uses a research and development design (research and development) designing a model developed by [11]. In this study the model used was developed with steps starting from the introduction with the activities of literature study and serving the field; training for participants and testing the effectiveness of teaching materials in improving the tutelary pedagogical competence.

\begin{tabular}{|c|c|}
\hline $\begin{array}{c}\text { Stage 1. Survey: } \\
\text { Identification of the needs of the civil } \\
\text { service community to learn about improving } \\
\text { pedagogical competencies }\end{array}$ & $\longrightarrow$ \\
\hline $\begin{array}{c}\text { Stage 4. Test Effectiveness: } \\
\text { Produce effective training teaching materials }\end{array}$ & \begin{tabular}{c} 
Stage 2. Development of Devices \\
Compile training teaching materials \\
Produce $\begin{array}{c}\text { valid training teaching } \\
\text { materials }\end{array}$ \\
\hline
\end{tabular} \\
\hline
\end{tabular}

Figure 1. Stages of Research

Data and data collection techniques in this study are: (a) data on problems and the need to improve tutors' competence through interviews; (b) data about the validity of teaching materials to improve the pedagogical competencies of civil service learning, obtained from expert academics, and practitioners (training instructors) using questionnaire validation sheets; and (c) data on the effectiveness of teaching training materials to improve pedagogical competence in teacher training, obtained by comparing the learning outcomes of participants before and after training using the test. The research subjects to test the effectiveness of teaching materials were 16 participants in the training. The effectiveness of the use of training teaching materials to improve pedagogical competencies in learning seen from the improvement of learning outcomes of trainees was analyzed using the N-Gain Test. This test is used to analyze the pre-test and post-test score data [12]. $<g>=\frac{<\text { Spost }>-<\text { Spre }>}{100 \%-<\text { Spre }>}$

\section{Result and Discussion}

\subsection{Problems and identification of training needed by the tutoring community}

The identification of training needs needed by the tutelary community in improving pedagogic competence was revealed through filling in interview guidelines that contained mastery statements and mastery tests related to pedagogical competencies which contained four sub-competencies, namely identification of students' initial needs, learning planning, 
learning implementation, and learning evaluation. The findings of the study indicate that the components of the context concerning the understanding of the tutors towards the residents are mostly $(63.3 \%)$ lacking in mastering the cognitive development of learning citizens, utilizing the principles of personality of the learning population, and lack of mastery in identifying /analyzing students' initial abilities, while the ability in designing learning, carrying out learning, and evaluating learning already felt to be sufficient.

Based on empirical data and analysis it can be stated that among the pedagogical competencies which contain four sub-competencies as described above, the ability to identify students' initial abilities is the most felt and needed by some tutors with a percentage of more than 75\%; and the ability to analyze process evaluation results and emphasize second learning ratings. Thus, training teaching material was developed to improve the pedagogical competencies of the tutors in this study which focused on improving the ability to identify students' initial abilities.

The implementation of the training is needed because several conditions include the following two conditions: (a) training is needed at the time of work which requires training participants to have skills, knowledge or attitudes that are different from or beside those currently owned, so they need to be expected to adjust to the main tasks and functions the responsibility; and (b) training is needed when progress in the organization requires individuals to have expertise, knowledge of different or new attitudes, in accordance with the demands of work and development of science and technology.

Thus, the training held must be based on the problems and real needs felt by tutors in improving their competencies. To determine the learning needs of participants in the training can be done using several methods and techniques, three learning approaches are suggested, namely a problem-centred approach, a projective approach, and a self-actualization approach [6]. The training learning process is a system. Thus, the achievement of process standards to improve the quality of the training learning process can be started by analyzing each component that can shape and influence the learning process. Learning training is a deliberate, purposeful and controlled effort so that other people learn and relatively permanent behavioural changes occur as a result of experience.

Efforts to make other people learn can be done by someone who can design, develop, utilize, manage, and assess the learning process. Learning contains more meaning than teaching as understood as presenting teaching materials. Learning is a personal mental process, takes place in active interaction with the environment to produce changes in knowledge, skills, and attitudes. A training learning is declared successful or effective if it can make active participants learn to build certain knowledge, skills and attitudes, improve learning outcomes, critical and creative thinking [13] [14]. In principle, training assessment activities are carried out before, while and after training learning. Based on the identification of the need for instructional materials needed in improving pedagogic competence, the Tutors is a teaching material to identify the characteristics of the needs of students. Broadly speaking, the teaching material prepared contains several parts, as follows: background, the purpose of writing instructional materials, expected results, and contents of teaching materials that explain basic competencies, description of teaching materials, assignments, and training.

\subsection{Effectiveness of training teaching materials}

The results of the validation calculation of four expert validators and related components of teaching materials consisting of the feasibility of content, presentation, and language are presented in the table as follows: 
Table 1. Summary of average results of the calculation of validation of teaching materials

\begin{tabular}{lcc}
\hline Component & Average Score & Category \\
& & \\
Content Feasibility & 3,31 & Very good \\
Presentation & 3,24 & Well \\
Linguistics & 3,27 & Well \\
& & \\
\hline
\end{tabular}

Based on the table above it is stated, the components: (a) the suitability of the content of the teaching material which includes the scope of the material consists of: conformity of materials with competency standards and basic training competencies, breadth of training material, and depth of material according to the training participants' abilities; and stimulating training participant activities which consist of: centered on training participants and training participants involvement, activities contained in teaching materials are able to encourage training participants' activities in training training, and the ability to motivate trainees in learning generally shows very good levels of categories; (b) presentation of teaching materials which contain: systematic consistency of presentation, logic of material presentation, and conceptual chaos; interactive communicative relationships and conformity with material characteristics, and the ability to stimulate the depth of thinking of trainees and supporters of presentations that contain supporting features of presentations (including introduction, table of contents, instructions to use, bibliography) generally indicate a good level of category; and (c) the language of teaching materials that contain communicative teaching materials about participant understanding, and the suitability of illustrations with the substance of reading in general, the innocence of teaching materials that contain the truth of sentence sentences and the suitability of terms, coherence and flow of thought. sentences, interrelationships between paragraphs, and reciprocal relationships between concepts, and conformity with Indonesian which contain language accuracy and spelling accuracy generally indicate a good level of category.

The research findings provide support for teaching materials prepared according to the training participants' needs. The effectiveness of teaching materials to improve PNS pedagogic competence in learning materials for approval and analysis of students 'initial learning abilities in this study requires through: (a) training participants' responses to prepared teaching materials, and (b) and N-Gain Tests used to analyze Improvement of learning outcomes of trainees. This test is used to analyze the pre-test and post-test score data. In general, participants' responses to teaching materials were used in training to improve pedagogical competencies in the average tutor learning category (84\%), meaning teaching materials showed a high level of effectiveness.

Exclusively the categories of responses of invited participants: (a) the size of teaching materials is in accordance with the standards with percentage $(89 \%)$, (b) the shape and size of letters used is clear and easy to read with percentage $(87 \%)$, (c) existing images in teaching materials are very interesting with a percentage $(88 \%)$, (d) the language used in teaching materials is easy to understand by percentage $(86 \%)$, (e) this teaching material helps me understand the material taught by the instructor with percentage $(81 \%)$, (f) a sense of interest in exploring teaching materials with a percentage $(82 \%),(\mathrm{g})$ teaching materials made me more active in learning activities with a percentage (85\%), (h) practice questions in teaching materials are easy to find and interesting to do with the percentage (84\%), (i) the content of instructional materials is useful to obtain knowledge about the ability to test and analyze 
students' initial abilities with percentages $(83 \%),(j)$ the growing sense of using these teaching materials in learning with pers entase $(84 \%),(\mathrm{k})$ this teaching material is more interesting to be assessed compared to existing teaching materials with a percentage $(86 \%)$, and (l) this teaching material is easier to use than existing teaching materials with $(87 \%)$.

Besides the participant's response, the method of measuring the effectiveness of training teaching materials was also carried out through written tests containing 10 (ten) multiplechoice questions and 2 (two) questions. The written test results for the pre-test and post-test of the training participants are presented in the table below.

Table 2. Mean comparison of training participants' pre-test and post-test results

\begin{tabular}{cc}
\hline Pre-test & \multicolumn{1}{c}{ Post-tes } \\
\hline 62,44 & $\mathrm{~N}=16$ \\
\hline & $\begin{array}{c}\mathrm{N}=43 \\
\text { Test the analysis of score data pre-test and post-test. } \\
\text { Included in the formula: }\end{array}$ \\
& $=0,4782,44$
\end{tabular}

A score of 0.4789 was then confirmed by the gain factor criteria in the quite high category. Thus, it is undeniable that the training teaching materials increase pedagogical competence in the material of approval and analysis of the students' initial ability, the level of effectiveness is quite high. In other words, material training teaching materials and analysis of students' initial abilities are quite effective in improving the learning outcomes of trainees. Effective training teaching materials will bring results to the continuity of a conducive learning process, and ultimately to the mastery of the training participants in the training material that is being delivered. The results of the study show teaching materials are designed to help participants connect what they know to what they expect in learning, and to build new knowledge from analysis and synthesis in the learning process [15] [7]. Other research findings explain how to develop an organization that can help develop training with teaching materials that are appropriate to the training participants' needs. [16] [17]. From the results of the test of the effectiveness of teaching materials that are appropriate in the high enough category, this indicates that there are still other factors associated with increasing the participation of trainees in training. Other factors that disprove the success of the trainees, the factor of training in resources, the learning resource factors, the motivational and disciplinary factors of the training participants, the facilities and infrastructure to support the training, and the factors needed from the training instructor.

\section{Conclusion}

Based on empirical data and analysis that can be submitted about pedagogical competencies which contain the four competencies that are appropriate above, the skills to improve students' abilities are the most needed and most needed problem by the tutors. Thus, the training teaching materials developed to improve the pedagogical competence of the civil 
servants in this study improves the competence of improving the ability of students. The effectiveness of teaching materials in terms of the response of the training participants showed a very responsive category, meaning teaching materials showed a high level of effectiveness in improving the pedagogic competence of the tutors. In other words, the training teaching materials developed were effective in improving the tutelary pedagogical competencies.

Acknowledgements. I also express my gratitude and appreciation to Tutors for helping the researchers from beginning to end. 


\section{Reference}

[1] Sutarto, Joko. Design of Training Based on Needs to Improve Pedagogic Competence of The Tutors. Advances in Social Science, Education and Humanities Research (ASSEHR), volume 66, 1st Yogyakarta International Conference on Educational Management/Administration and Pedagogy. pp. 102-107 (2017).

[2] Kruidering-Hall., Vereijken, M.W.C., Jong, P.G.M., Beaufort, A.J., \& Dekker, F.W. Scientific education early in the curriculum using a constructivist approach on learning. Perspect Med Educ, 6 (2). pp. 209-215 (2013).

[3] Valanides, N., Papageorgiou, M., \& Charoula Angeli. Scientific Investigations of Elementary School Children. J Sci Educ Technol, 23. pp. 26-36 (2014)

[4] Ratcliffe, Mary. Science Literacy and Scientific Values: Implication for Formal Education. Rend Fis Acc Lincei 23(1). pp. 535-538 (2012).

[5] Diane, D. 2007. Organizational change and work-related empowerment. Journal of Nursing management. Vol 15. pp. 500-507.(2007).

[6] Srinivasan, Lyra, Perspectives On Non-Formal Adult Learning, New York: World Education (1997).

[7] Movahedzadeh, F. 2011. Improving Students' Attitude Toward Science Through Blended Learning. Journal Science Education and Civic Engagement. 3 (2).pp. 13-19 (2015).

[8] Heering, P., Klassen, S., \& Metz, D. Enabling Scientific Understanding Through Historical Instruments and Experiments in Formal and Non-formal Learning Environments. Sci \& Educ, 3 (24). Pp. 339-341 (2015).

[9] Fenwick, T., \& Edwards, R. Exploring the impact of digital technologies on professional responsibilities and education. European Educational Research Journal, 15(1). pp. 117-131 (2016).

[10] Claire A. Surr and Cara Gates. Effective Dementia Education and Training for the Health and Social Care Workforce: A Systematic Review of the Literature. Review of Educational Research October 2017, Vol. 87, No. 5, pp. 966-1002 (2017).

[11] Borg and Gall. Educational Research, An Introduction. New York and London. Longman Inc. (1989).

[12] Heck, H.Ronal. Principals Instructional Leadership and School Performance Implications for Policy Development, Educational Evaluation and Policy analysis Vol 14, N0.1 pp 21-34 (2002). University of Hawaii at Manoa.

[13] Kocman, Mugla Sitki. The effective presentation of inquiry-based classroom experiments using teaching strategies that employ video and demonstration methods. Australasian Journal of Educational Technology. 29 (3). (2013)

[14] Nagl, M.G., Obradovic, D.Z., \& Segedinac, M.. Effective Teaching of Physics and Scientific Method. TEM Journal, 1 (2). pp. 85-89 (2012).

[15] Hudson, Clemente C. dan Vesta R. Whisler. Contextual Teaching and Learning for Practitioners. Journal of Systemics, Cybernetics and Informatics. 6 (4). pp. 54-58 (2007).

[16] Neomi Kaplan-Mor, Chanan Glezer, M. Z. A comparative analysis of end-user training methods. Journal of Systems and Information Technology, 13(1). pp. 25-42 (2011).

[17] Marques Vieira, Rui \& Tenreiro-Vieira, Cellina. "Fostering Scientific Literacy and Critical Thinking in Elementary Science Education". Int J of Sci and Math Educ, 10: 1-22 (2015). 